\title{
Needle-Knife Fistulotomy as a Rescue Access of the Common Bile Duct in Cirrhotic Patients: Feasibility and Outcome
}

\author{
Yasser A El-Naggar ${ }^{1}$, Mohamed I Radwan ${ }^{2}$, Mohamed H Emara ${ }^{2}$ \\ ${ }^{I}$ Internal Medicine Department, Faculty of Medicine, Zagazig University, Egypt \\ ${ }^{2}$ Tropical Medicine Department, Faculty of Medicine, Zagazig University, Egypt.
}

See editorial page: 115 Corresponding Author
Mohamed I Radwan

Mobile:

$+201068887285$

E mail:

drmmagdy@yahoo.co

$m$

Key words:

Endoscopic retrograde cholangiopancreatogra phy; needle-knife fistulotomy; cannulation, cirrhosis, common bile duct; pancreatitis
Background and study aim: Cannulation of the common bile duct may require invasive procedures; such procedures may carry an increased risk of complications. This study aimed at comparing the safety and efficacy of the needle-knife fistulotomy with other techniques in cirrhotic patients after failure of the standard cannulation using the free hand needle knife.

Patients and methods: Seventy cirrhotic patients were included and were divided into: Group $\mathrm{A} ; 15$ patients who underwent a needle-knife fistulotomy using the needle-knife after failure of transpapillary wire - guided cannulation. Group B : 15 patients who underwent a precut using the standard pull sphincterotome after failure of transpapillary wire - guided cannulation. Group C : 20 patients who underwent a conventional transpapillary wire - guided cannulation without sphincterotomy. Group D : 20 patients who underwent a conventional

\section{INTRODUCTION}

Endoscopic

retrograde cholangiopancreatography (ERCP) is the standard approach for the diagnosis and treatment of a wide variety of hepatopancreaticobiliary diseases. Since its development, it has gained widespread use and has become a therapeutic tool in that field [1].

Cannulation of common bile duct (CBD) requires many techniques, these include standard transpapillary biliary cannulation techniques with the use of catheters and papillotome [2] with or without the use of a guide wire [3]; placement of a pancreatic guide wire (or stent) to assist biliary cannulation [4]; precut "access" papillotomy, by using a needle knife or a traction papillotome [5]; and transpapillary wire - guided cannulation with standard sphincterotomy. Cannulation was evaluated for duration, number of trials, use of aiding instruments and success rate.

Results: Success rate of CBD cannulation and fair dye drainage was reported in $93.3 \%$ and $73.3 \%, 86.7 \%$ and $80 \%, 85 \%$ and $70 \%, 85 \%$ and $80 \%$ of patients in groups $\mathrm{A}, \mathrm{B}, \mathrm{C}$ and $\mathrm{D}$ respectively, with no statistically significant difference among the four groups. The only complication reported in group A was bleeding (three patients). No statistically significant difference among the four groups regarding post-procedural complications was noticed.

Conclusion: Suprapapillary needle knife fistulotomy can be used in cirrhotic patients when standard biliary cannulation proves to be difficult, it is associated with a high success rate and a low complication risk.

papillectomy [6] may also be used. The suprapapillary needle puncture technique is another technique that could be added to those techniques in cases with difficult cannulation [7].

Operations (including ERCP) in patients with existing liver disease are not uncommon and the peri-operative risk increases with advanced stage of liver disease [8].

The aim of this work was to evaluate and compare the safety and efficacy of the needle-knife fistulotomy technique in cirrhotic patients using the free hand needle knife with other techniques used for biliary access after failure of the standard transpapillary biliary cannulation as regard immediate and long term outcomes. 


\section{PATIENTS AND METHODS}

Study design: Prospective randomized.

Study setting and time: This study was conducted on patients from the Gastrointestinal Endoscopy Units of both the Internal Medicine and Tropical Medicine Departments -Zagazig University Hospitals, Egypt in the period from March 2011 to September 2012 and operated upon at ERCP unit of the Tropical Medicine Departments -Zagazig University Hospitals, Egypt. One experienced endoscopist with annual ERCP rate of >200 case/year performed all cases.

Patients: Out of 322 ERCP patients, 70 cirrhotic patients (Child A and B) were included.

\section{Exclusion criteria : Exclusion of patients with}

- Prior ERCP.

- Prior gastric surgery.

- Child-Pugh class C patients.

- The patient did not consent for all or part of the expected procedures.

The severity of hepatic dysfunction in patients with chronic liver disease has been classified according to the modified Child-Pugh classification [9] as shown in Table 1.

\section{Study groups:}

- Group A : 15 patients who underwent a needle-knife fistulotomy using the needle-knife as an access to the CBD after failure of transpapillary wire - guided cannulation.

- Group B : 15 patients who underwent a precut using the standard pull sphincterotome as an access to the bile duct after failure of transpapillary wire - guided cannulation.

- Group C : 20 patients who underwent a conventional transpapillary wire - guided cannulation without sphincterotomy.

- Group D : 20 patients who underwent a conventional transpapillary wire - guided cannulation with standard sphincterotomy.

\section{Definitions :}

Cannulation failure: defined as up to three unintended cannulations of the pancreatic duct or failure of biliary cannulation attempts within a time limit of 10 minutes [10].
Difficulty of cannulation was graded according to the total number of attempts on the major papilla with all devices, before final cannulation of the CBD. Difficulty of cannulation was described as "easy" one to five attempts, "moderate" six to fifteen attempts, and "difficult" more than fifteen attempts [11].

Primary outcome: was successful cannulation of the CBD with comparison of the four procedures as regard the time needed for successful cannulation and adverse events.

Secondary outcomes: were post- ERCP adverse events.

Diagnostic failure was considered when the CBD could not be cannulated. Therapeutic failure was defined as the lack of adequate duct drainage when necessary.

ERCP was considered successful i.e. clinically effective if there were partial or complete relief of symptoms associated with sonographic evidence of relief.

Post-ERCP Pancreatitis : Defined as the recording of pancreatic enzymes levels greater than three times the normal upper limits, associated with severe abdominal pain requiring narcotic analgesics for at least 24 hours (requiring more than one night of hospitalization) [12].

Cholangitis: Defined as a fever greater than $38^{\circ}$ $\mathrm{C}$ for more than 24 hours that was thought to have biliary causes, chills, elevated liver enzymes, and/or positive blood culture within 48 hours after the procedure [12].

Perforation: Defined as slight leakage of contrast during ERCP or evidence of retroperitoneal or free air on abdominal radiographs and computed tomography (CT) [12].

Bleeding : Defined as either "immediate" if it is apparent during precut or sphincterotomy and required endoscopic hemostasis, and "delayed" if the patient post-procedural develop melena or drop in hemoglobin $(\mathrm{Hb})$ level greater than $2 \mathrm{~g} / \mathrm{dl}$ or the need for a blood transfusion [12].

Adverse events were classified as mild if the length of hospital stay was less than or equal to 3 nights; moderate 4-9 nights and severe if: 10 or more nights admission, admission to an intensive care unit, or required surgery. As regard timing, adverse events were considered "immediate" if they occurred during or shortly after the 
procedure within one hour ; "early" if they occurred within $1-48$ hours ; and "delayed" if occurred after 2 days [14].

\section{Ethical Considerations:}

The study was approved by the Ethical Committee of the Faculty of Medicine, Zagazig University. The patient or his custodian gave a written consent for the procedure after explaining the risk/benefit ratio as well as expected hazards and interventions.

\section{All patients were subjected to:}

\section{- Before ERCP :}

- Thorough history taking.

- Thorough clinical examination.

- Investigations including :

A. Laboratory: Liver function tests, kidney function tests, prothrombin time (PT), complete blood count (CBC) and serum amylase.

B. Radiological: Abdominal ultrasound \pm CT \pm MRCP.

C. Other investigations: Chest $\mathrm{X}-$ ray, ECG and Echocardiography (for selective cases).

D. Preparation of the patients for ERCP:

a- Patients received vitamin $\mathrm{K}$ (Phytonadione solution IV, $10 \mathrm{mg} /$ day) for 3 days before ERCP. Fresh frozen plasma $(10-15 \mathrm{ml} / \mathrm{kg})$ was given immediately before the endoscopy if the prothrombin time was > 16 seconds [15].

\section{- During ERCP :}

- ERCP was performed under general anesthesia with intravenous $1 \%$ propofol in the presence of an anesthesiologist in 64 patients. The remaining 6 patients were deeply sedated with intravenous Pethidine $(50 \mathrm{mg})$ and Midazolam $(10 \mathrm{mg})$ due to their advanced Child class B score.

- ERCP was done and cannulation was viewed from four perspectives, namely :

- Duration.

- Number of trials (each targeting was considered as an individual trial).

- Use of aiding instruments and methods

- Success rate.

\section{A. Suprapapillary needle - knife fistulotomy CBD:}

Performed by using a needle knife at a point corresponding to the proximal third of the line between the transversal fold and the papillary ostium, at least five millimeters above the orifice, perpendicular to the papilla at 11-12 O'clock position, and three millimeters deep to the surface (over the most bulging point of the pregnant papilla; on the bulged intraduodenal segment of the CBD extending upward or downward over the papillary mound).

After needle puncture of the CBD was confirmed by easy insertion of a guide wire parallel to the spine in the direction of the CBD then injection of the contrast medium to obtain a cholangiogram (here there is no pancreatogram). If the guide wire insertion into the CBD did not occur easily, gentle lateralization movements were carried out, with simultaneous attempts to pass the guide wire.

The procedure was completed according to the diagnosis in each case (stone extraction, biliary dilatation and brush cytology, stent insertion in selected cases).

\section{B. Precut by pull sphincterotome:}

It is an incision of the papillary roof which is carried out from the papillary orifice along the midline of the papilla. The incision is made in small increments by using pure cutting current to ensure a clean cut. The aim is to slit open the papillary roof in order to expose the orifice of the CBD.

\section{C.Transpapillary cannulation without sphincterotomy :}

It is the standard cannulation of the CBD through the papillary orifice by using diagnostic biliary cannulae of different sizes, the guide wire was used to facilitate cannulation.

\section{Transpapillary cannulation with standard sphincterotomy:}

It is the standard cannulation of the CBD through the papilla, but by using a sphincterotome for both cannulation and standard sphincterotomy.

\section{- Post ERCP :}

- Patients were allowed to drink and eat as soon as they have fully recovered from anesthesia and intestinal movements were regained, except if adverse events were expected when 
nil per os (NPO) and infusion of intravenous fluids were followed for variable durations.

- Patients received IV antibiotics (Cefotaxime), vitamin $\mathrm{K}$, antispasmodics whenever needed.

- All patients were admitted for at least one day (the night after the procedure) and the patients with evident or suspected post - ERCP adverse events had longer durations of hospital stay, and upon discharge the patients and their relatives were given detailed instructions about symptoms of post - ERCP adverse events and were informed to report by phone or to come to the emergency unit or outpatient clinics if any symptoms suggestive of post-ERCP adverse events developed.

- Repeated clinical evaluation of all patients daily during hospital stay.

- Investigations were done one day after the procedure, and within one week in patients with suspected early post-ERCP adverse events.

Follow up of all patients during the hospital stay and for 2 weeks after discharge as outpatients for detection of clinical efficacy of the procedure. Cases with failed ERCP were subjected to either repetition of ERCP (but were not re-included in this study), referral to surgery or percutaneuos transhepatic drainage according to the individual situation. Recording mortality during hospital stay and for 2 weeks after discharge.

\section{Statistical analysis:}

Data were checked, entered and analyzed using SPSS version 15. Data were expressed as mean \pm $\mathrm{SD}$ for quantitative variables, number and percentage for qualitative ones. Chi-squared $\left(\mathrm{X}^{2}\right)$ or Fisher exact, $t$ test and paired $t$ test were used when appropriate. $\mathrm{P}<0.05$ was considered significant.

\section{RESULTS}

Out of 322 ERCP cases presented to our units in the study period, 70 cirrhotic cases Child A and B were enrolled in a percent of $21.7 \%$, this reflects the high prevalence of chronic liver diseases in our community. The base line characteristics of patients are shown in Table 2. A total of 37 females (53\%) and 33 males (47\%) with mean age 56.3 years (range $28-78$ years) were included. The commonest indication for
ERCP was CBD stones followed by pancreatic masses.

A total of 30 patients (42.8\%) had comorbidities. Cardiovascular diseases (hypertension, ischemic heart diseases and heart failure were the comments associated morbidities) followed by diabetes and COPD. These associated co-morbidities were not associated with an added risk to ERCP adverse events in this study (Figure 1).

Cannulation of the CBD succeeded in group A in 93.3\% of cases with fair drainage of the dye in $73.3 \%$ of them, $86.7 \%$ of cases in group B with fair drainage of dye in $80 \%$ of them, $85 \%$ of cases in group $\mathrm{C}$ with fair drainage of dye in $70 \%$ of them and lastly $85 \%$ of cases in group D with fair drainage of dye in $80 \%$ of them, with no statistically significant difference among the studied groups regarding the cannulation success rate $(\mathrm{p}=0.87)$ or the fair drainage of the biliary tree $(\mathrm{p}=0.76)$ (Figure 2).

No post ERCP pancreatitis was reported in group A, while the incidence was $6.7 \%, 5 \%$ and $10 \%$ in groups $\mathrm{B}, \mathrm{C}$ and $\mathrm{D}$ respectively. Regarding the severity of pancreatitis according to Cotton et al., [12], one case in group B and another one in group $\mathrm{C}$ presented by mild form, while in group $\mathrm{D}$ the two cases presented by moderate degree. They were treated conservatively in the hospital then discharged within $8-10$ days. There were no severe cases and there was no mortality related to pancreatitis.

Bleeding was the most common complication in this study. Intra-operative bleeding was reported in two, one, one and two cases in groups A, B, C and $\mathrm{D}$ respectively. Bleeding was mild and stopped either by cautery or after diluted adrenaline flushing, while delayed bleeding (all presented with melena) was reported in one case in each of groups A, B and C and two cases in group $\mathrm{D}$, and was treated conservatively and with blood transfusion, neither surgery nor therapeutic angiography were needed in all cases.

A case of cholangitis was reported in group D which resolved with medical treatment, while there were no cases in the other groups. Hepatic encephalopathy (HE) developed in one case of Child's class B (score 9) in group C. No cases of perforation were recorded in this study.

The developed adverse events when translated to terms of prolonged hospital stay (more than 3 days) occurred as follow: three cases in group A, 
three cases in group B, five cases in group C and seven cases in group D.

The only case of mortality among the groups was recorded in group $\mathrm{C}$ and he died due to $\mathrm{HE}$ in spite of admission to the hepatology intensive care.

In this study there was a significant relation of post - ERCP pancreatitis with the number of trials and the duration taken for cannulation, with more attempts to cannulate more time is elapsed and more risk to develop post-ERCP pancreatitis (Table 4). There was a significant relation of ERCP related bleeding and the prolonged prothrombin time and this is reflected in terms of intra-operative and delayed bleeding episodes, although the bleeding was not fatal (Table 5). Only one case of cholangitis was reported in this series. She was a female patient in the group D and this was controlled with iv levofloxacin injection once daily for 5 days.

The total number of cases achieved an overall success were 58 cases $(82.85 \%)$. Group A showed a better overall success which was achieved in 14 cases $(93.3 \%)$, group B showed an overall success in 13 cases $(86.6 \%)$, group $\mathrm{C}$ showed an overall success in 17 cases $(85 \%)$ and group D showed an overall success in 14 cases $(70 \%)$ with no statistically significant difference among the studied groups. The parameters assessed to evaluate the overall success were: Successful CBD cannulation and absence of post - ERCP adverse events (Figure 3).

Table (1): The modified Child - Pugh classification

\begin{tabular}{|l|c|c|c|}
\hline \multirow{2}{*}{ Parameter } & \multicolumn{3}{|c|}{ Numerical score } \\
\cline { 2 - 4 } & $\mathbf{1}$ & $\mathbf{2}$ & $\mathbf{3}$ \\
\hline Ascites & None & Slight & Moderate to severe \\
\hline Encephalopathy & None & Grade I - II & Grade III - IV \\
\hline Bilirubin & $<2 \mathrm{mg} / \mathrm{dl}$ & $2-3 \mathrm{mg} / \mathrm{dl}$ & $>3 \mathrm{mg} / \mathrm{dl}$ \\
\hline Albumin & $>3.5 \mathrm{mg} / \mathrm{dl}$ & $2.8-3.5 \mathrm{mg} / \mathrm{dl}$ & $<2.8 \mathrm{mg} / \mathrm{dl}$ \\
\hline $\begin{array}{l}\text { Prothrombin time (seconds }> \\
\text { control) }\end{array}$ & $1-3$ & $4-6$ & $>6$ \\
\hline
\end{tabular}

Child - Pugh class $A=$ score $5-6$, class $B=$ score $7-9$, class $C=$ score $10-15$

Table (2): shows base line data of the studied patients

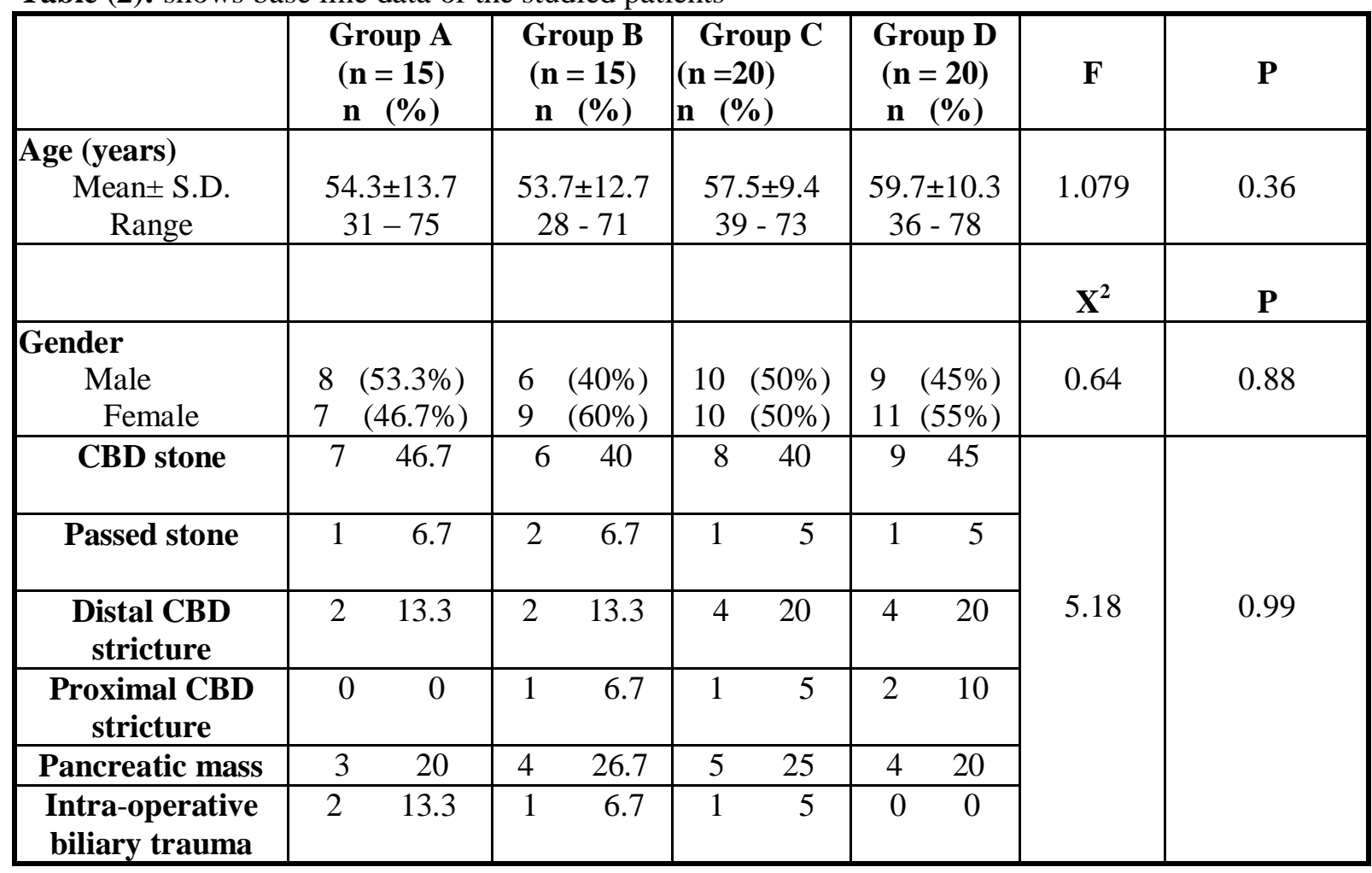


Table (3): Reported complications in the studied groups.

\begin{tabular}{|c|c|c|c|c|c|c|c|c|c|c|c|c|}
\hline & & \multicolumn{2}{|c|}{$\begin{array}{c}\text { Group A } \\
(\mathbf{n}=\mathbf{1 5})\end{array}$} & \multicolumn{2}{|c|}{$\begin{array}{c}\text { Group B } \\
(\mathbf{n}=15)\end{array}$} & \multicolumn{2}{|c|}{$\begin{array}{c}\text { Group C } \\
(\mathbf{n}=\mathbf{2 0})\end{array}$} & \multicolumn{2}{|c|}{$\begin{array}{c}\text { Group D } \\
(\mathbf{n}=\mathbf{2 0})\end{array}$} & \multicolumn{2}{|c|}{$\begin{array}{c}\text { Total } \\
(n=70)\end{array}$} & \multirow[t]{2}{*}{$\begin{array}{c}P \\
\text { value }\end{array}$} \\
\hline & & $\mathbf{N}$ & $\%$ & n & $\%$ & n & $\%$ & $\mathbf{N}$ & $\%$ & n & $\%$ & \\
\hline \multicolumn{2}{|c|}{ Pancreatitis $(n=4)$} & 0 & 0 & 1 & 6.7 & 1 & 5 & 2 & 10 & 4 & $5.7 \%$ & 0.65 \\
\hline \multirow{2}{*}{$\begin{array}{c}\text { Bleeding } \\
(\mathbf{n}=11)\end{array}$} & immediate & 2 & 13.3 & 1 & 6.7 & 1 & 5 & 2 & 10 & 6 & $8.5 \%$ & 0.82 \\
\hline & delayed & 1 & 6.7 & 1 & 6.7 & 1 & 5 & 2 & 10 & 5 & $7.1 \%$ & 0.39 \\
\hline \multicolumn{2}{|c|}{ Cholangitis $(n=1)$} & 0 & 0 & 0 & 0 & 0 & 0 & 1 & 5 & 1 & $1.4 \%$ & 0.46 \\
\hline \multicolumn{2}{|c|}{$\begin{array}{l}\text { Hepatic encephalopathy } \\
(\mathrm{n}=1)\end{array}$} & 0 & 0 & 0 & 0 & 1 & 5 & 0 & 0 & 1 & $1.4 \%$ & 0.65 \\
\hline \multicolumn{2}{|c|}{$\begin{array}{c}\text { Prolonged hospital stay } \\
(\mathrm{n}=18)\end{array}$} & 3 & 20 & 3 & 20 & 5 & 25 & 7 & 35 & 18 & $25 \%$ & 0.7 \\
\hline \multicolumn{2}{|c|}{ Mortality $(n=1)$} & 0 & 0 & 0 & 0 & 1 & 5 & 0 & 0 & 1 & $1.4 \%$ & 0.65 \\
\hline
\end{tabular}

Table (4): The possible risk factors for post-ERCP pancreatitis among the studied groups.

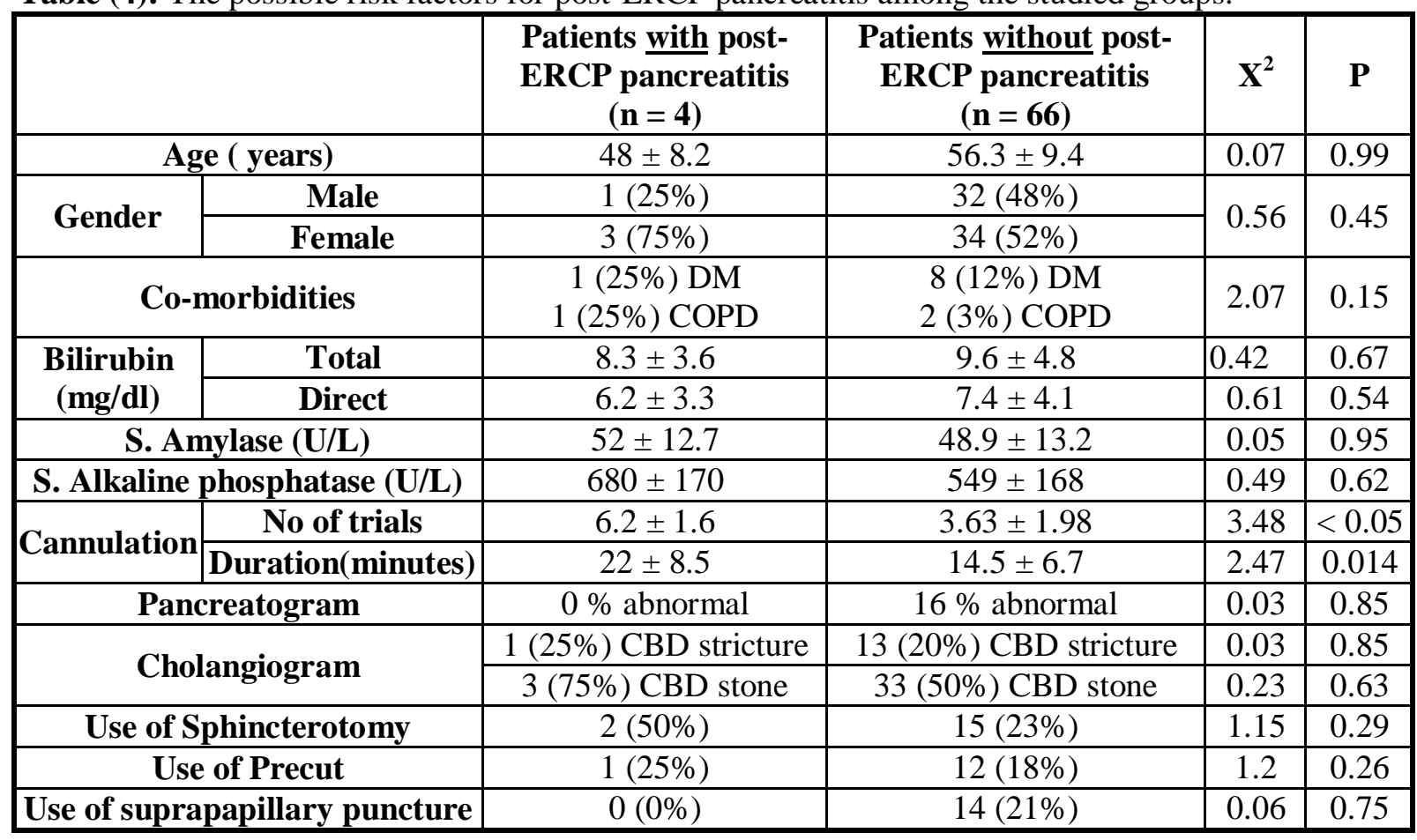

Table (5): The possible risk factors for bleeding among the studied groups.

\begin{tabular}{|c|c|c|c|c|c|}
\hline & $\begin{array}{c}\text { Patients with } \\
\text { bleeding } \\
(\mathbf{n}=11)\end{array}$ & $\begin{array}{c}\text { Patients without } \\
\text { bleeding } \\
(n=59)\end{array}$ & $\mathbf{X}^{2}$ & $\mathbf{P}$ \\
\hline \multicolumn{2}{|c|}{ Age ( years) } & $47 \pm 6.2$ & $54 \pm 8.4$ & 0.05 & 0.85 \\
\hline \multirow{2}{*}{ Gender } & Male & $9(81 \%)$ & $24(40 \%)$ & \multirow{2}{*}{0.55} & \multirow{2}{*}{0.45} \\
\hline & Female & $2(19 \%)$ & $35(60 \%)$ & & \\
\hline \multicolumn{2}{|c|}{ PT (seconds) } & $14 \pm 1.5$ & $11.8 \pm 1.16$ & 2.3 & $<0.05$ \\
\hline \multicolumn{2}{|c|}{ Platelets (x 10\%/cc) } & $149.5 \pm 73$ & $236 \pm 76$ & 1.32 & 0.22 \\
\hline \multirow{2}{*}{ Cannulation } & No of trials & $3.7 \pm 2.1$ & $3.8 \pm 1.3$ & 0.71 & 0.51 \\
\hline & Duration (minutes) & $15 \pm 9.5$ & $14.6 \pm 8.2$ & 0.6 & 0.55 \\
\hline \multicolumn{2}{|c|}{ Cholangiogram } & $7(65 \%)$ CBD stone & $\begin{array}{l}29(49 \%) \text { CBD stone } \\
14(24 \%) \text { CBD stricture }\end{array}$ & 0.28 & 0.59 \\
\hline \multicolumn{2}{|c|}{ Use of Sphincterotomy } & $4(36 \%)$ & $13(22 \%)$ & 0.14 & 0.7 \\
\hline \multicolumn{2}{|c|}{ Use of Precut } & $2(18 \%)$ & $13(22 \%)$ & 0.55 & 0.52 \\
\hline \multicolumn{2}{|c|}{ Use of suprapapillary puncture } & $3(27 \%)$ & $12(20 \%)$ & 0.89 & 0.62 \\
\hline
\end{tabular}


Table (6): The possible risk factors for post-ERCP cholangitis among the studied groups.

\begin{tabular}{|c|c|c|c|c|c|}
\hline \multicolumn{2}{|c|}{ Factor } & $\begin{array}{c}\text { Patients with } \\
\text { cholangitis } \\
(n=1)\end{array}$ & $\begin{array}{c}\text { Patients without } \\
\text { cholangitis } \\
(n=69)\end{array}$ & $\mathbf{X}^{2}$ & $\mathbf{P}$ \\
\hline \multicolumn{2}{|c|}{ Age ( years) } & 60 & $56.3 \pm 11.5$ & 1.2 & 0.72 \\
\hline \multirow[t]{2}{*}{ Gender } & Male & $0(0 \%)$ & $33(48 \%)$ & \multirow[t]{2}{*}{0.01} & \multirow[t]{2}{*}{0.92} \\
\hline & Female & $1(100 \%)$ & $36(52 \%)$ & & \\
\hline \multicolumn{2}{|c|}{ Co-morbidities } & $1(100 \%) \mathrm{DM}$ & $8(11.5 \%) \mathrm{DM}$ & 1.43 & 0.23 \\
\hline \multirow{2}{*}{$\begin{array}{c}\text { Bilirubin } \\
\text { (mg/dl) }\end{array}$} & Total & 15 & $9.75 \pm 5.1$ & 0.13 & 0.88 \\
\hline & Direct & 11 & $7.27 \pm 4.2$ & 0.07 & 0.93 \\
\hline \multicolumn{2}{|c|}{ S. Amylase (U/L) } & 51 & $48 \pm 4$ & 0.41 & 0.68 \\
\hline \multicolumn{2}{|c|}{ S. Alkaline phosphatase (U/L) } & 655 & $547 \pm 75$ & 1.35 & 0.12 \\
\hline \multirow[t]{2}{*}{ Cannulation } & No of trials & 6 & $3.8 \pm 1.2$ & 0.85 & 0.6 \\
\hline & Duration (minutes) & 20 & $14.5 \pm 9.4$ & 0.46 & 0.64 \\
\hline \multicolumn{2}{|c|}{ Pancreatogram } & $0(0 \%)$ Abnormal & $11(16 \%)$ Abnormal & 1.2 & 0.27 \\
\hline \multicolumn{2}{|c|}{ Cholangiogram } & $1(100 \%)$ CBD stone & $31(45 \%)$ CBD stone & 1.06 & 0.3 \\
\hline \multicolumn{2}{|c|}{ Use of Sphincterotomy } & $1(100 \%)$ & $16(23 \%)$ & 0.14 & 0.7 \\
\hline \multicolumn{2}{|c|}{ Use of Precut } & $0(0 \%)$ & $15(22 \%)$ & 1.43 & 0.23 \\
\hline \multicolumn{2}{|c|}{ Use of suprapapillary puncture } & $0(0 \%)$ & $14(20 \%)$ & 0.1 & 0.75 \\
\hline
\end{tabular}

Figure (1): The patients' co-morbidities

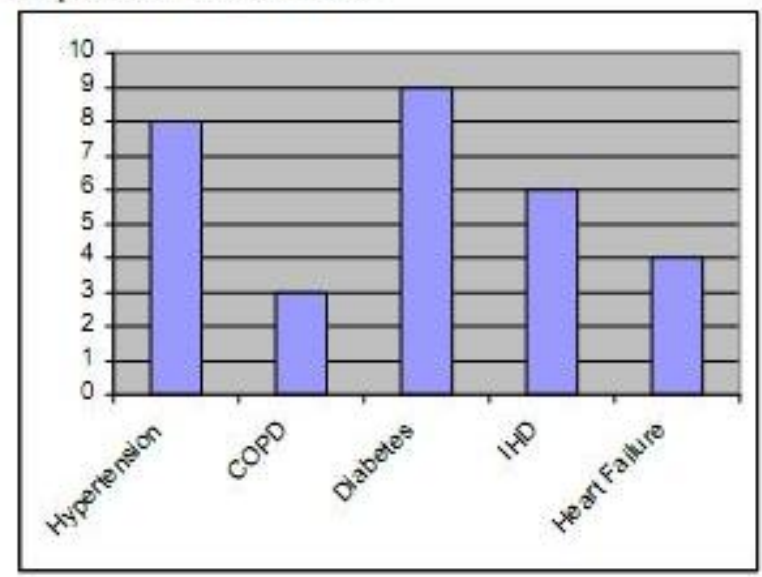

COPD chronic obstructive pulmonary disease, $1 \mathrm{HD}$ ischemic heart disease

Figure (2): The successful cannulation rates among the studied groups.

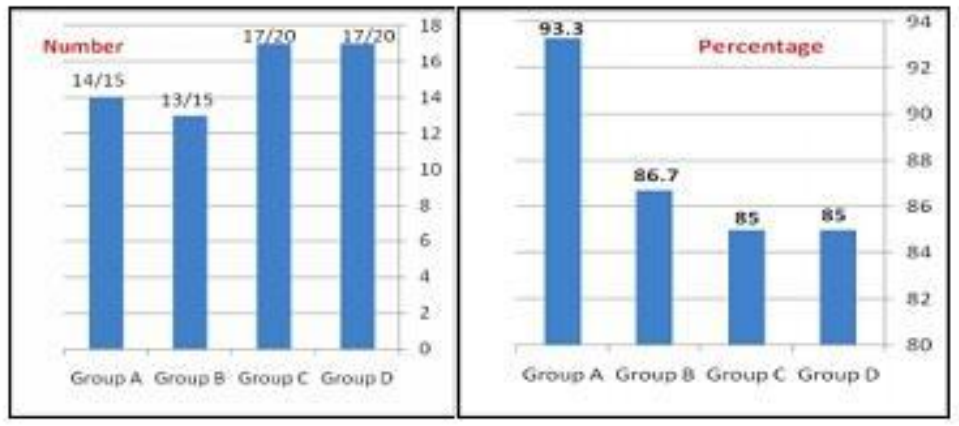


Figure (3): The overall success rates among the studied groups.

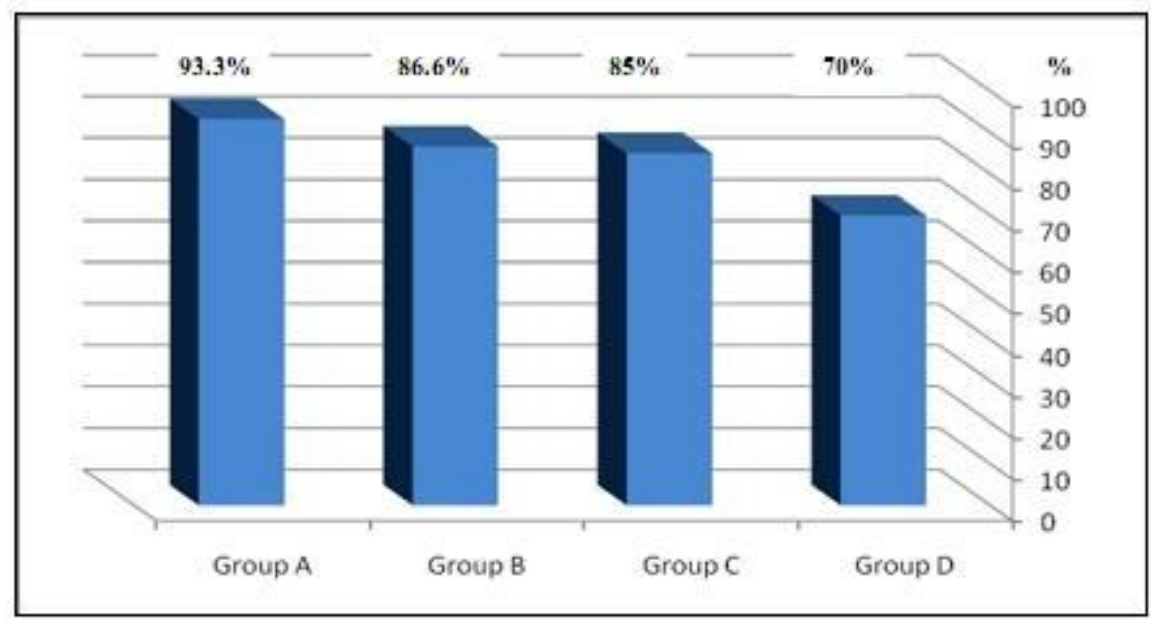

\section{DISCUSSION}

Cannulation of the CBD remains the most important and challenging aspect of the ERCP. Even in experienced hands the cannulation through the papillary orifice may be difficult [16]. Consequently, several techniques have been developed to facilitate cannulation of the papilla during ERCP [17]. The problem of canulation is expected to be more difficult in cirrhotic patients who are known to be more vulnerable to operative risks in particular the bleeding episodes.

In this study, we look to the suprapapillary puncture technique previously used by Everson et al in 2007 [7] who accomplished this technique by a specially designed needle as a rescue in order to overcome difficult cannulation in the subgroup of cirrhotic patients who tolerate invasive techniques poorly. Because of unavailability of this needle in our work, needle - knife was used for the fistulotomy technique

The mean age of our patients was $56.3 \pm 9.4$ years. Therapeutic ERCP is safe and effective and well tolerated in elderly patients so advanced age per se should not impinge on decisions relating to its use [18]. This study confirmed that elderly cirrhotic patients can tolerate therapeutic ERCP when properly selected and prepared.

Although, liver diseases in Egypt are common in males than females [19], females predominates in this study and this may be related to the biliary stone disease that was the comments indication for ERCP in this series a finding agrees with other studies [20], such category of diseases are more frequent in females.

Irrespective of the technique used, successful cannulation of the CBD was achieved in $87 \%$ (61/70) of cases, $85 \%$ (53/61) of the successfully cannulated cases achieved fair drainage of the biliary tree. These results lie central within the range of cannulation success rates reported by many authors varying from $80 \%$ to $95 \%$ [21-23].

In the present study, suprapapillary needle knife fistulotomy appeared to be superior to other methods, as successful cannulation of the CBD was achieved in $93.3 \%$ of cases, while other precut techniques using the sphincterotome achieved $86.6 \%$ and $85 \%$ success rate for the remaining two groups with no added risk.

The high success rate with the needle-knife fistulotomy of $93.3 \%(14 / 15)$ in our study is comparable with rates of $86 \%-90.5 \%$ reported by many authors [24-25]. Precut techniques success rate was $86.6 \%(13 / 14)$ in the present study and is comparable to Vandervoort et al., [26] who reported a rate of $86 \%(120 / 140)$ and Deng et al., [23] who reported a rate of $89 \%$ (247/277).

The adverse events following the ERCP can occur approximately in $10 \%$ of cases and mortality in about 1\% [11]. This is the range within which figures from a great number of published series lay and also our study lies.

Regarding the post - ERCP pancreatitis that has been developed after the procedure, the overall incidence in our study was $5.7 \%$ with no statistically significant difference among the 
studied groups, which is in line with the reported rates of $4-5.5 \%$ in other studies $[27,28]$.

There were no reported cases of pancreatitis after the suprapapillary puncture technique in our study. This is because the potential mechanisms that precipitate pancreatitis associated with conventional transpapillary biliary cannulation and endoscopic sphincterotomy were avoided. .

Chemical, allergic and hydrostatic injury to the pancreatic duct from inadvertent injection of contrast into the pancreatic duct is eliminated by totally avoiding the pancreatic duct injections and selectively injecting into the bile duct only after confirmation of the position of the guide wire in the bile duct.

Thermal injury from conventional biliary sphincterotomy was also avoided, because balloon dilation of the puncture tract was used to enlarge the orifice for removal of stones in selected cases. The hypothesis that avoidance of thermal injury to the pancreatic duct by means of cutting above the papillary orifice minimizes risk for pancreatitis seems to be reinforced by the results of this study, although the concept remains controversial [29].

The question about the needle - knife technique is whether or not the observed adverse events rate is a function of the technique itself, or merely a reflection of the fact that the repeated unsuccessful cannulation after standard techniques has been difficult and the prolonged attempts to achieve cannulation may result in trauma and inflammation of the papilla with the resultant edema accounting for the increased rate of pancreatitis. Before the needle - knife was used in difficult biliary cannulation, the risk of overall adverse events had already reached $14 \%$, but with the early institution of the needle - knife the successful biliary access was increased while the overall adverse events rate was reduced to $11.8 \%$ [30].

We used all measures to minimize the risk of post - ERCP pancreatitis such as tapered catheters, avoiding repeated pancreatic cannulations and effort to cannulate the CBD in a programmed, step - by - step manner, for no more than 10 minutes and, we also tried to use coagulation current and avoidance of working on non - dilated CBD. However, the higher rates of post - ERCP pancreatitis recorded were assumed to be related to the repeated cannulation attempts that have been occurred before precut. These repeated cannulation attempts also mean that precut was almost performed under difficult conditions, on an already edematous and distorted papilla.

The incidence of pancreatitis following standard sphincterotomy in the present study was $10 \%$ which is relatively higher than $5.4 \%$ rate reported by Freeman et al., [11], this may be attributed to the relatively long duration for cannulation in group D patients 18.4 minutes (range $8-40$ minutes) and the use of sphincterotome as the cutting wire tend to inadvertently injure the juxtapapillary portion of the pancreatic duct, leading to a cascade of events that culminates in pancreatitis.

The possible risk factors for post - ERCP pancreatitis in our study were significantly related to the number of trials for transpapillary cannulation $(p<0.05)$ and also to the duration spent for attempting transpapillary cannulation $(\mathrm{p}$ $=0.014)$.

As regard the overall bleeding risk in the present study it was $8.5 \%$ for immediate bleeding and $7.1 \%$ for the delayed bleeding with no statistically significant difference among the studied groups. As regard the bleeding risk in the needle - knife fistulotomy group (group A) it was $13.3 \%$ for immediate bleeding and $6.7 \%$ for delayed bleeding that agreed with results of Donnellan et al. [31].

The relatively high rate of bleeding in our study is directly related to the underlying liver disease (prolonged PT) and might be also related to the use of pure cutting current for fistulotomy and other precutting techniques. We expected a higher rate of bleeding episodes than we reported and we assume that iv pre-operative vitamin $\mathrm{K}$ and fresh frozen plasma are responsible for this reduction.

In the present study, HE after ERCP has occurred in one patient $(1.4 \%)$. The only significant risk factor for its development was advanced chronic liver disease (Child's class B). The enhanced effect of sedation with the relatively long procedure time could explain the development of $\mathrm{HE}$ in this patient.

In our study, prolonged hospital stay (more than three days) occurred in $25 \%$ of cases. This could be explained by the high rate of co-morbidity $(42.8 \%)$ in this study; association of liver cirrhosis with other chronic diseases explains the long hospital stay for complicated cases. 
Mortality rate was $1.4 \%$, as only one patient died 7 days after the procedure from HE. Mortality rate in our study lies close to mortality rates reported by many authors that range from $0.16 \%$ to $1 \%[26,27,32]$.

\section{CONCLUSION}

In this study we concluded that suprapapillary needle - knife fistulotomy can be used when standard biliary cannulation proves to be difficult, it is associated with a high success rate and a low complication risk in experienced hands even in cirrhotic patients it can be used as an alternative method, at least in difficult patients.

\section{Funding: Non.}

Conflicts of interest: The authors declare that there is no conflict of interest.

Ethical approval: Was granted by the hospital ethics committee and informed consent was obtained from each patient prior to inclusion in the study.

\section{REFERENCES}

1. Cotton PB, Leung J. Advanced Digestive Endoscopy: ERCP Book, $1^{\text {st }}$ ed., Charleston: Blackwell Publishing 2006; $1: 1-7$.

2. Cortas GA, Mehta SN, Abraham NS, Barkun AN. Selective cannulation of the common bile duct : A prospective randomized trial comparing standard catheters with sphincterotomes. Gastrointest Endosc 1999; 50: 775 - 779.

3. Lella F, Bagnolo F, Colombo E, Bonassi U. A simple way of avoiding post - ERCP pancreatitis. Gastrointestinal Endoscopy $2004 ; 59: 830$ 834.

4. Freeman ML, Overby C, Qi D. Pancreatic stent insertion: Consequences of failure and results of a modified technique to maximize success. Gastrointestinal Endoscopy $2004 ; 59: 8$ - 14.

5. Burdick JS, London A, Thompson DR. Intramural incision technique. Gastrointestinal Endoscopy $2002 ; 55$ (3) : $425-427$.

6. Farrell RJ, Khan MI, Noonan N, O'Byrne K, Keeling PW. Endoscopic papillectomy : A novel approach to difficult cannulation. Gut $1996 ; 39$ : $36-38$.

7. Everson LA, Paulo SM, Shinichi IM, Fabio YH. Suprapapillary puncture of the common bile duct for selective biliary access: A novel technique. Gastrointestinal Endoscopy 2007; 65: $124-131$.

8. Rädle J, Rau B, Kleinschmidt S, Zeuzem S. Operative Risk in Patients with Liver and
Gastrointestinal Diseases. Dtsch Arztebl 2007; 104(26): A 1914-21.

9. Pugh RN. Pugh's grading in the classification of liver decompensation. Gut $1992 ; 33$ (11) : 1583.

10.Zhou PH, He GJ, Yao LQ, et al. The application of needle knife sphincterotomy in the treatment of ampulla obstructive diseases. China $J$ Endosc 2002; $8: 1-3$.

11.Freeman ML, Nelson DB, Sherman S, Haber GB, Herman ME, Dorsher PJ et al. Complications of endoscopic biliary sphincterotomy. $N$ Engl $J$ Med. 1996 ; 335 : 909 - 918.

12.Cotton PB, Lehman G, Vennes J, Geenen JE, Russell RC, Meyers WC, et al. Endoscopic sphincterotomy complications and their management : An attempt at consensus. Gastrointest Endosc 1991; 37: 383 - 393.

13.Detrenis S, Meschi M, Bertolini L, Savazzi G. Contrast Medium Administration in the Elderly Patient: Is Advancing Age an Independent Risk Factor for Contrast Nephropathy after Angiographic Procedures? J Vasc Interv Radiol $2007 ; 18: 177-185$.

14.Pannu HK, Fishman EK. Complications of ERCP : Spectrum of abnormalities demonstrated with CT. Radiographics 2001; 21 (6) : 1441 1453.

15.Amir T. Disorders of hemostasis. In : Shubhada NA, Kellie F, Subramanian P, eds. The Washington Manual of Medical Therapeutics $30^{\text {th }}$ ed., Lippincott Williams \& Wilkins 2001; 18 : $511-544$.

16.Zhou PH, Yao LQ, Xu MD, Zhong YS, Gao $\mathrm{WD}, \mathrm{He}$ GJ, et al. Application of needle - knife in difficult biliary cannulation for ERCP. Hepatobiliary Pancreat Dis Int 2006 ; 5 : 590 594.

17. Garcia-Cano LJ, Gonzalez-Martin JA. Bile duct cannulation : Success rates for various ERCP techniques and devices at a single institution. Acta Gastroenterol Belg 2006; 69: 261 - 267.

18.Katsinelos P, Paroutoglou G, Kountouras J, Zavos C, Beltsis A, Tzovaras G. Efficacy and safety of therapeutic ERCP in patients 90 years of age and older. Gastrointest Endosc 2006 ; 63 : 417 423.

19.Salem GA, El-Gamal NE, Abd El-Aziz MB, Hassan R. Different Treatment Modalities for Improving HCV Response. Afro-Egypt $J$ Infect Endem Dis 2012; 2(3): 95-103

20.Ong TZ, Khor JL, Selamat DS, Yeoh KG, Ho KY. Complications of ERCP in the post-ERCP era : A tertiary center experience. World $J$ Gastroenterology 2005; $11(33)$ : 5209 - 5212. 
21.Zinsser E, Hoffmann A, Will U, Koppe P, Bosseckert H. Success and complication rates of diagnostic and therapeutic ERCP : A prospective study. Z Gastroenterol. 1999 ; 37 : 707 - 713.

22.Cotton PB. Income and outcome metrics for the objective evaluation of ERCP and alternative methods. Gastrointest Endosc 2002; 56 : 283 290.

23.Deng DH, Zuo HM, Wang JF, Gu ZE, Chen $\mathrm{H}$, Luo $\mathrm{Y}$, et al. New precut sphincterotomy for ERCP in difficult biliary duct cannulation. World J Gastroenterol 2007 ; 13 : 4385 - 4390.

24.Mavrogiannis C, Liatsos C, Romanos A, Petoumenos C, Nakos A, Karvountzis G. Needle knife fistulotomy versus needle - knife precut papillotomy for the treatment of common bile duct stones. Gastrointest Endosc 1999 ; 50 : 334 339.

25. Khatibian M, Sotoudehmanesh R, Ali-Asgari A, Movahedi Z, Kolahdoozan S. Needle - knife fistulotomy versus standard method for cannulation of common bile duct: a randomized controlled trial. Arch Iran Med 2008; 11 : 16 20.

26.Vandervoort J, Soetikno RM, Tham TC, Wong RC, Ferrari AP Jr, Montes $\mathrm{H}$ et al. Risk factors for complications after performance of ERCP. Gastrointest Endosc 2002;56: 652 - 656.
27.Garcia-Cano LJ, Gonzalez-Martin JA, Mirilas AJ, Pérez Sola A. Complications of ERCP : A study in a small ERCP unit. Rev Esp Enferm Dig 2004 ; $96: 163-173$.

28.Katsinelos P, Mimidis K, Paroutoglou G, Christodoulou K, Pilpilidis I, Katsiba D, et al. Needle - knife papillotomy : A safe and effective technique in experienced hands. Hepatogastroenterology 2004; 51 : 349 - 352.

29.Freeman ML. Complications of endoscopic biliary sphincterotomy : A review. Endoscopy $1997 ; 29: 288-297$.

30.Carr-Locke DL. Biliary access during ERCP. Can J Gastroenterol 2004; 18 : 251 - 254.

31.Donnellan F, Zeb F, Courtney G, Aftab AR. Suprapapillary needle - knife fistulotomy : A safe and effective method for accessing the biliary system. Surg Endosc 2010;24: 1937 - 1940.

Peer reviewer: Ahmed I El-Maaddawy, Consultant Hepatologist, Kafr El-Shiekh Liver Research Centre; Mahmoud A Soliman, Assistant professor of Tropical Medicine and Hepatogastroenterology, Faculty of Medicine, Mansoura University, Egypt.

Editor: Tarik I Zaher, MD, Professor of Tropical Medicine, Faculty of Medicine, Zagazig University, Egypt. 